\title{
The relevance of Short-Term Variation (STV) value measured within 1 hour before delivery in predicting adverse neonatal outcome
}

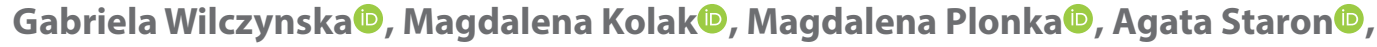 \\ Daniel Lipka®i, Malgorzata Radon-Pokracka@, Hubert Huras(1) \\ Department of Obstetrics and Perinatology, Jagiellonian University Medical College, Cracow, Poland
}

\begin{abstract}
Objectives: Computer CTG analysis ( $\mathrm{CCTG)}$ included short-term variation (STV) is one of the methods of monitoring fetal condition during delivery. The aim of our study was to define appropriability of STV measured within 1 hour before delivery in prediction of neonatal outcomes.

Material and methods: The retrospective study included 1014 pregnant women, who gave birth in the Department of Obstetrics and Perinatology. Participants were divided into two groups: group 1 - term pregnancies (37-41 weeks) and group 2 - preterm pregnancies (lower than 37 weeks). In each of them, two subgroups have been separated: control (STV $\geq 3 \mathrm{~ms}$ ) and study group (STV $<3 \mathrm{~ms}$ ).

Results: In both groups 1 and 2, there were no statistically significant differences related to Apgar scores in $1^{\text {st }}, 3^{\text {rd }}$ and $5^{\text {th }}$ minute between group with STV $<3 \mathrm{~ms}$ and group with STV $>3 \mathrm{~ms}$ Moreover, for 37-41 weeks the sensitivity, specificity, positive predictive value and negative predictive value were: $22.7 \%, 83.9 \%, 3.3 \%$ and $97.8 \%$ and for lower than $37: 45.7 \%$, $65.4 \%, 47.1 \%, 64.2 \%$ in $1^{\text {st }}$ minute after delivery. In group 1 the area under curve (AUC) measurements were $0.45(95 \% \mathrm{Cl}$ : $0.32-0.58)$ for $1^{\text {st }}$ minute and $0.55(95 \% \mathrm{Cl}: 0.35-0.74)$ for $5^{\text {th }}$ minute and in group $2: 0.58(95 \% \mathrm{Cl}: 0.45-0.71)$ for $1^{\text {st }}$ minute and 0.57 (95\% Cl: $0.42-0.72)$ for $5^{\text {th }}$ minute.

Conclusions: High specificity and negative predictive value of STV indicates a good Apgar score of newborns in term pregnancies. Analysis of STV in preterm pregnancy is not clear. Fetal well-being in preterm pregnancy should include STV and other non-invasive and invasive tools.
\end{abstract}

Key words: cardiotocography (CTG); short-term variation; intrapartum monitoring; APGAR score

Ginekologia Polska 2021; 92, 12: 878-883

\section{INTRODUCTION}

Cardiotocography (CTG) is one of the basic examinations in obstetrics, which enables assessment of fetal heart rate and uterine contractions. However, this method might be considered as subjective and associated with poor interand intraobserver reproducibility in the interpretation of CTG trace. One might state that the computer CTG analysis (cCTG) is more objective, and its results are unambiguous [1]. One of the parameters measured during CCTG is a short-term variation (STV). STV analyses the variability of the fetal heart rate from beat to beat and cannot be interpreted visually [2]. There are currently no studies that would perform research on a large number of patients, assessing the importance of STV during delivery monitoring.

\section{Objectives}

The innovative approach of the research covers establishing the place of STV concerning the prediction of intrapartum hypoxia. The first aim of this study was to find dependence between Apgar score and STV. Secondly, we wanted to define the diagnostic accuracy of STV: sensitivity, specificity, positive and negative predictive values (PPV and NPV). The third goal was to analyse ROC curves based on

\footnotetext{
Corresponding author:

Gabriela Wilczynska

Department of Obstetrics and Perinatology, Jagiellonian University Medical College, Cracow, Poland

e-mail: gabriela-wilczynska@wp.pl
} 
the results. Finally, to find out a connection between STV value and the way of delivery.

\section{MATERIAL AND METHODS}

Between March and December 2017, a total of 2516 patients gave birth in the University Hospital of the Department of Obstetrics and Perinatology of the Jagiellonian University Medical College in Cracow, Poland, which is a tertiary referral hospital. The analysis was performed on 1014 women, who met the following criteria: single pregnancies, continuous CTG monitoring in the last hour before delivery. Informed consent was obtained from all individuals participating in the study. The exclusion criteria were multiple pregnancies, elective caesarean section (lack of continuous monitoring before delivery), fetal anomalies and fetal growth restriction (FGR).

Patients were divided into two groups according to gestational age: Group 1 - term pregnancy - gestational age between 37 and 41 weeks (927 patients) and Group 2 - preterm birth - gestational age less than 37 weeks (87 patients). In each group, the patients were additionally separated into subgroups based on their STV value: study group with STV value lower than 3 milliseconds (In term group: $\mathrm{n}=157$, preterm group: $\mathrm{n}=34$ ); and control group - STV higher or equal to 3 milliseconds (in term group: $n=770$ and preterm group: $n=53$ ). (Fig. 1) [1].

2516 women delivered in the Department of Obstetrics and Perinatology, Jagiellonian University Medical College in Cracow, Poland between March and December 2017

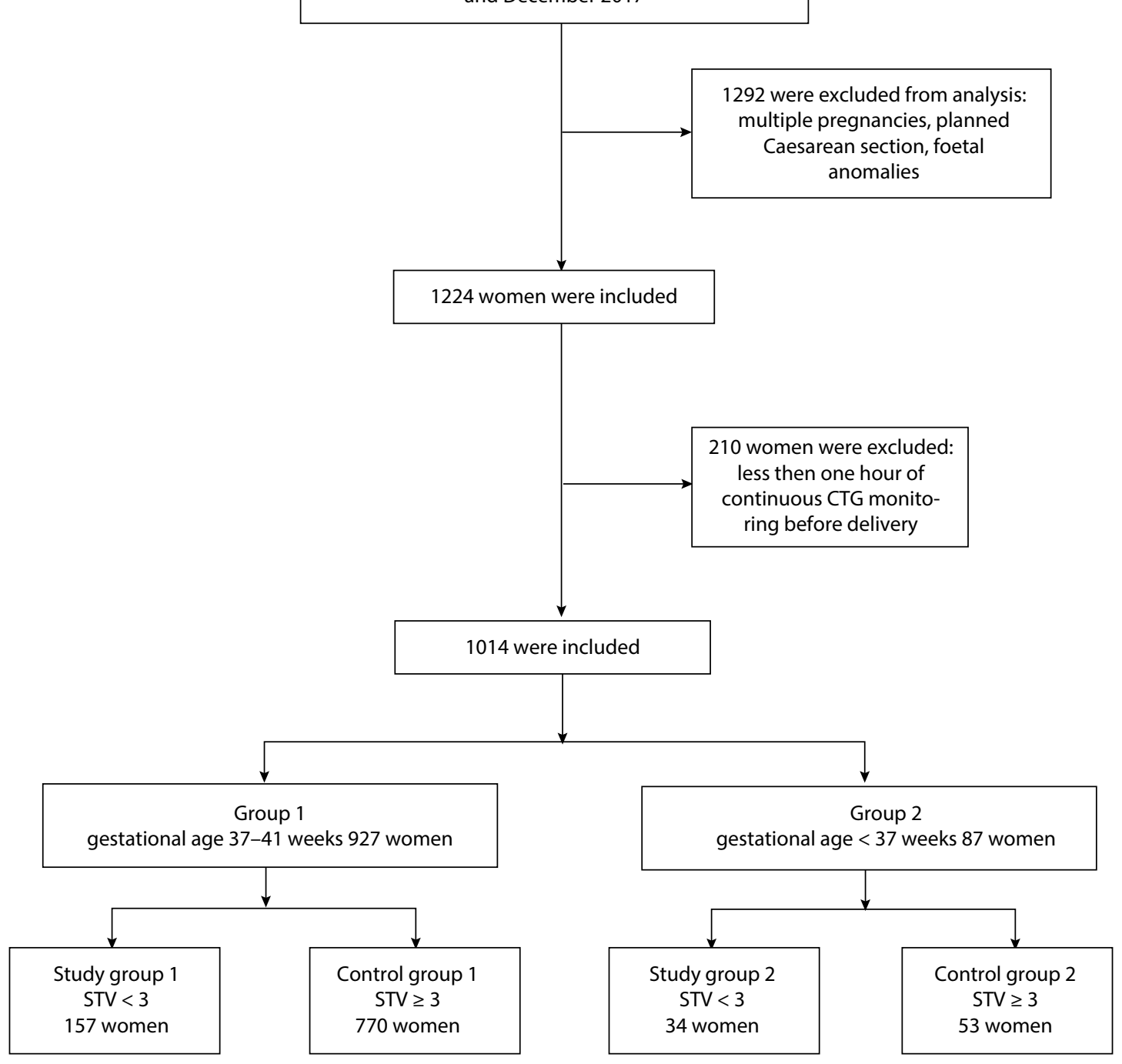

Figure 1. Analysis of patients in the study; STV — Short-Term Variation; CTG — cardiotocography 
All cardiotocography measurements were performed by doctors from the Department of Obstetrics and Perinatology of the Jagiellonian University. The STV values were calculated using a MONAKO system which facilitates non-invasive fetal monitoring based on computer analysis of cardiotocography signals: fetal heart rate, uterine contractions, and fetal movement. According to Combined Fetal Monitoring Guideline (GL964), the cut-off points for STV were 3 milliseconds and correlated with stillbirth and severe birth acidemia [1]. We assumed that Apgar score lower than 8 in $5^{\text {th }}$ minute was a negative endpoint.

All information about the patients, including age, number of pregnancies, number of labours and BMI, were taken from the patients' case notes. According to WHO recommendations, preterm birth was defined as given before 37 completed weeks of gestation [3]. Neonatal outcomes were evaluated using Apgar score in $1^{\text {st }}, 3^{\text {rd }}$ and $5^{\text {th }}$ minute. Perinatal outcome involved a caesarean section for obstetrical indications in labour.

The data was analysed using STATISTICA 13.1 software. $2 \times 2$ table was used to calculate point true positive (STV $<3$, Apgar score $<8$ ), false positive (STV $<3$, Apgar score $\geq 8$ ), false negative (STV $\geq 3$, Apgar score $<8$ ), and true negative (STV $\geq 3$, Apgar score $\geq 8$ ) values [4]. The normality was tested using Shapiro-Wilk test. Due to not fulfilled parametric test perquisites, relationships between qualitative and quantitative variables were assessed with Chi-squared test and Mann-Whitney $U$ test, respectively. A value of $\mathrm{p}<0.05$ was considered statistically significant. ROC curve which illustrates the diagnostic ability of STV to assess its clinical usefulness was utilised. Area under curve (AUC) was calculated for the study groups for Apgar score in $1^{\text {st }}$ and $5^{\text {th }}$ minutes [5]. The study was approved by the Bioethics Committee of the Jagiellonian University.

\section{RESULTS}

In term group, we found out that both subgroups, control and study, did not differ significantly in terms of demographic and obstetrical characteristics except for gestational age $(39.13 \pm 3.58$ vs $39.39 \pm 1.05 p=0.01)$. Statistical differences were present, but for clinical practice, it had no significance. In the preterm group, study and control subgroups also did not differ in terms of baseline characteristics. In this group, there was a statistically significant difference in terms of gestational age between study and control subgroup (31.94 \pm 3.58 vs $33.45 \pm 2.88, p=0.03)$. In both, term and preterm group, there were no significant differences in terms of using oxytocin in the first and second stage of labour between study and control subgroups. Basic parameters were compared between groups and the results are shown in Table 1.

The first aim of the study concerned establishing a difference in Apgar score depending on STV values. This score, created by Virginia Apgar, in the early 1950s, is still universally used to assess newborns' health. Low Apgar score (0-3 or 4-6) for preterm infants may reflect physiologic immaturity, it could be caused by drugs, infections, congenital anomalies. It is associated with an increased risk of neonatal and infant mortality, both in term and preterm pregnancies [6]. In both groups 1 and 2, there were no statistically significant differences related to Apgar scores in $1^{\text {st }}, 3^{\text {rd }}$ and $5^{\text {th }}$ minute between the group with STV $<3$ milliseconds and group with STV > 3 milliseconds (Tab. 2).

To analyse the second aim of our research, we calculated point estimates of sensitivity, specificity, positive predic-

Table 1. Demographic and obstetrical characteristics of the study and the control groups

\begin{tabular}{|l|l|l|l|}
\hline Group 1 & Study group 1 & Control group 1 & p value \\
\hline Characteristics & $29.96 \pm 4.29$ & $30.31 \pm 4.67$ & 0.28 \\
\hline Maternal age [years] & $1.85 \pm 1.12$ & $1.77 \pm 0.97$ & 0.55 \\
\hline Number of pregnancies & $1.61 \pm 0.89$ & $1.55 \pm 0.73$ & 0.78 \\
\hline Parity & $22.17 \pm 3.42$ & $22.26 \pm 1.11$ & 0.95 \\
\hline BMI [kg/m²] & $39.13 \pm 1.15$ & $39.39 \pm 1.05$ & 0.01 \\
\hline Gestational age [weeks] & & & \\
\hline Group 2 & Study group 2 & Control group 2 & p value \\
\hline Characteristics & $31.24 \pm 5.44$ & $30.98 \pm 4.89$ & 0.82 \\
\hline Maternal age [years] & $2.12 \pm 1.27$ & $1.74 \pm 1.06$ & 0.11 \\
\hline Number of pregnancies & $1.82 \pm 1.06$ & $1.49 \pm 0.75$ & 0.15 \\
\hline Parity & $22.82 \pm 4.94$ & $22.90 \pm 3.76$ & 0.5 \\
\hline BMI [kg/m²] & $31.94 \pm 3.58$ & $33.45 \pm 2.88$ & 0.03 \\
\hline Gestational age [weeks] & & & \\
\hline BM-body mass & & \\
\hline
\end{tabular}

$\mathrm{BMI}$ - body mass index 
Table 2. Apgar score in $1^{\text {st }}, 3^{\text {rd }}$ and $5^{\text {th }}$ minute in term and preterm pregnancies

\begin{tabular}{|l|l|l|l|}
\hline Group 1 & \multicolumn{2}{l|}{} \\
\hline Characteristics & Study group 1 & Control group 1 & p value \\
\hline Apgar score in $1^{\text {st }}$ minute & $9.77 \pm 0.82$ & $9.81 \pm 0.63$ & 0.93 \\
\hline Apgar score in $3^{\text {rd }}$ minute & $9.83 \pm 0.60$ & $9.89 \pm 0.47$ & 0.38 \\
\hline Apgar score in $5^{\text {th }}$ minute & $9.85 \pm 0.59$ & $9.91 \pm 0.44$ & 0.3 \\
\hline Cesarean section [\%] & 16.56 & 9.79 & 0.01 \\
\hline Group 2 & & & p value \\
\hline Characteristics & Study group 2 & Control group 2 & 0.12 \\
\hline Apgar score in $1^{\text {st }}$ minute & $7.47 \pm 2.06$ & $8.11 \pm 1.99$ & 0.26 \\
\hline Apgar score in $3^{\text {rd }}$ minute & $8.18 \pm 1.49$ & $8.54 \pm 1.47$ & 0.39 \\
\hline Apgar score in $5^{\text {th }}$ minute & $9.85 \pm 1.31$ & $9.91 \pm 1.24$ & 0.002 \\
\hline Cesarean section [\%] & 61.76 & 28.30 & \\
\hline
\end{tabular}

\begin{tabular}{|c|c|c|}
\hline & $\begin{array}{l}\text { Apgar score } \\
\text { in } 1^{\text {st }} \text { minute }\end{array}$ & $\begin{array}{l}\text { Apgar score } \\
\text { in } 5^{\text {th }} \text { minute }\end{array}$ \\
\hline & $\begin{array}{l}\text { percent } \\
(95 \% \mathrm{Cl})\end{array}$ & $\begin{array}{l}\text { percent } \\
(95 \% \mathrm{Cl})\end{array}$ \\
\hline \multicolumn{3}{|l|}{ Whole group of patients } \\
\hline Sensitivity & $36.8(24.4-50.7)$ & $44.8(26.4-64.3)$ \\
\hline Specificity & $82.8(80.3-85.2)$ & $82.5(80.0-84.9)$ \\
\hline $\begin{array}{l}\text { Positive predictive value } \\
\text { (PPV) }\end{array}$ & $11.3(7.2-16.8)$ & $7.0(3.8-11.7)$ \\
\hline $\begin{array}{l}\text { Negative predictive value } \\
\text { (NPV) }\end{array}$ & $95.7(94.0-96.9)$ & $98.1(96.9-98.9)$ \\
\hline \multicolumn{3}{|l|}{ Group 1} \\
\hline Sensitivity & $22.7(7.8-45.4)$ & $45.5(16.7-76.6)$ \\
\hline Specificity & $83.9(81.3-86.2)$ & $84.1(81.5-86.4)$ \\
\hline $\begin{array}{l}\text { Positive predictive value } \\
\text { (PPV) }\end{array}$ & $3.3(1.1-7.6)$ & $3.3(1.1-7.6)$ \\
\hline $\begin{array}{l}\text { Negative predictive value } \\
\text { (NPV) }\end{array}$ & $97.8(96.5-98.7)$ & $99.2(98.3-99.7)$ \\
\hline \multicolumn{3}{|l|}{ Group 2} \\
\hline Sensitivity & $45.7(28.8-63.4)$ & $44.4(21.5-69.2)$ \\
\hline Specificity & $65.4(50.9-78.0)$ & $62.3(49.8-73.7)$ \\
\hline $\begin{array}{l}\text { Positive predictive value } \\
\text { (PPV) }\end{array}$ & $47.1(29.8-64.9)$ & $23.5(10.7-41.2)$ \\
\hline $\begin{array}{l}\text { Negative predictive value } \\
\text { (NPV) }\end{array}$ & $64.2(49.8-76.9)$ & $81.1(68.0-90.6)$ \\
\hline
\end{tabular}

$\mathrm{Cl}$ - confidence interval

tive value (PPV) and negative predictive value (NPV), using $2 \times 2$ tables. Table 3 shows the diagnostic accuracy of STV in term and preterm pregnancies. Sensitivity is the ability of test (in this case STV) to correctly identify those with the disease (for our study - Apgar score lower than 8), whereas specificity enables identify those without the disease. Positive or negative predictive value relates to the utility of test
Table 4. Utility of Apgar score shows as area under curve

\begin{tabular}{|c|c|}
\hline & AUC $(95 \% \mathrm{Cl})$ \\
\hline \multicolumn{2}{|l|}{ Whole group of patients } \\
\hline Apgar score in $1^{\text {st }}$ minute & $0.59(0.51-0.68)$ \\
\hline Apgar score in $5^{\text {th }}$ minute & $0.66(0.56-0.77)$ \\
\hline \multicolumn{2}{|l|}{ Group 1} \\
\hline Apgar score in $1^{\text {st }}$ minute & $0.45(0.32-0.58)$ \\
\hline Apgar score in $5^{\text {th }}$ minute & $0.55(0.35-0.74)$ \\
\hline \multicolumn{2}{|l|}{ Group 2} \\
\hline Apgar score in $1^{\text {st }}$ minute & $0.58(0.43-0.69)$ \\
\hline Apgar score in $5^{\text {th }}$ minute & $0.57(0.42-0.72)$ \\
\hline
\end{tabular}

$\mathrm{Cl}$ - confidence interval; AUC — area under curve

(STV) to confirm or rule out threat of ischemia for a newborn [7]. In term group, high specificity and negative predictive value of STV, both connected with Apgar in $1^{\text {st }}$ and $5^{\text {th }}$ minute, are noticed.

To assess the third aim of the study, we calculated STV predicts neonatal outcomes (Apgar in $1^{\text {st }}$ and $5^{\text {th }}$ min.) in the whole group of patients and for subgroups - preterm and term (Tab. 4). A ROC curve (receiver operating characteristic curve) is a graphical plot illustrating the diagnostic ability of a binary test thus allowing researchers and medical personnel to assess its clinical usefulness (Fig. 2-4). Area under curve (AUC) was calculated for the study groups for Apgar score in $1^{\text {st }}$ and $5^{\text {th }}$ minutes. In Group 1 the AUC measurements were 0.45 (95\% Cl: $0.32-0.58)$ for first minute and 0.55 (95\% Cl: 0.35-0.74) for fifth minute and in Group 2: 0.58 (95\% Cl: 0.45-0.71) for the first minute and 0.57 (95\% Cl: 0.42-0.72) for the fifth minute [8].

The last aim was to analyse the connection between STV and route of delivery. Concerning term pregnancies, in the study group $16.56 \%$ of patients had a caesarean section, and in the control group, it was to $9.79 \%$. A statistically significant difference was recognised $(p=0.01)$. In the preterm group there 


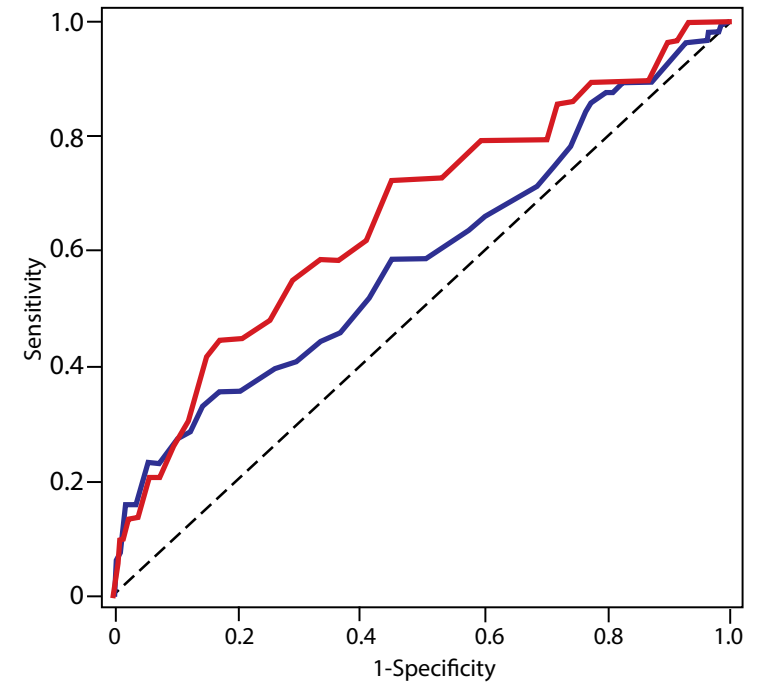

Figure 2. ROC analysis for whole group (blue $-1^{\text {st }}$ minute, red $-5^{\text {th }}$ minute)

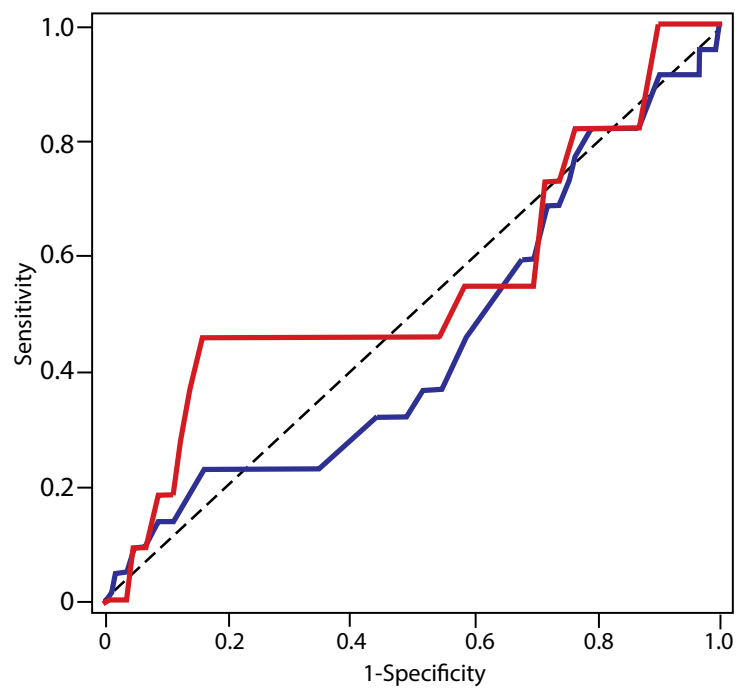

Figure 3. ROC analysis for term pregnancies (blue $-1^{\text {st }}$ minute, red $-5^{\text {th }}$ minute)

was also a statistically significant difference between study and control group (61.76\% vs $28.30 \% \mathrm{p}=0.002$ ) (Tab. 2.) For all 137 patients on whom caesarean section was performed, the most common indications were threatened fetal asphyxia ( $n=50,36.50 \%)$ and prolonged labour $(n=48,35.04 \%)$. Other indications included: placental abruption ( $n=15,10.95 \%)$, pre-eclampsia ( $n=11,8.03 \%)$, abnormal delivery mechanism ( $n=9,6.57 \%)$, abnormal Doppler ultrasound $(n=2,1.46 \%)$ and umbilical cord prolapse $(n=2,1,46 \%)$. Prolonged labour was the most common indication for term group of patients ( $n=48,47.52 \%$ ) and threatened fetal asphyxia in preterm group ( $n=12,33.33 \%$ ). The second most common for term group was threatened fetal asphyxia $(n=38,37.62 \%)$ and concerning preterm, placental abruption $(n=11,30.56 \%)$.

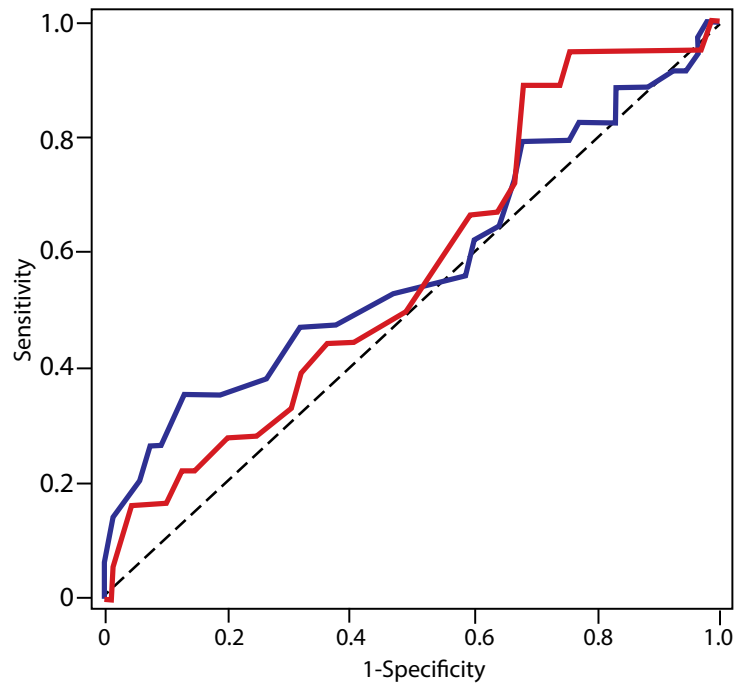

Figure 4. $\mathrm{ROC}$ analysis for preterm pregnancies (blue $-1^{\text {st }}$ minute, red $-5^{\text {th }}$ minute)

\section{DISCUSSION}

Cardiotocography is a part of electronic fetal heart rate monitoring (EFM), which aim is to determine fetal well-being and detect signs of intrapartum hypoxia. EFM was introduced in the 1960s and was the first equipment based on phonocardiography which was later substituted by Doppler signals, which lead to significant improvement on the quality of the signals [9]. One of the main aims of STV analysis was to detect intrapartum fetal distress. However, there were no significant differences in Apgar score results between subgroups with normal and abnormal STV value found. Our study is consistent with Leszczynska-Gorzelak et al. [10], paper, which shows that low STV could coexist with a good result in Apgar score. The study presents that low STV is connected with a decrease in fetal blood saturation in the $2^{\text {nd }}$ stage of labour. It shows that CCTG is insufficient to evaluate fetal hypoxia, therefore, some analyses involve drawing blood from a fetal scalp which is an invasive procedure. It was believed that CCTG could have been gold standard assessment [11].

According to the diagnostic accuracy of STV, term pregnancies have high results concerning the specificity and negative predictive value, which allows to exclude fetal hypoxia, if STV is over 3 milliseconds. There are only a few papers, which analyse sensitivity, specificity, PPV and NPV of CTG parameters. Giuliano et al. [12], analyses 9 parameters of CTG (including STV); in healthy pregnancies from $30^{\text {th }}$ to $42^{\text {nd }}$ gestational week, with specificity and NPV: 89\%, 93.7\% respectively. One might spot a problem concerning a group of preterm pregnancies - sensitivity, specificity, positive predictive value and negative predictive value are similar. Also, the ROC curve's shape and low AUC strongly suggest low diagnostic ability with AUC values being close to the worst pos- 
sible 0.5 . In our study, STV has poor positive predictive value which is consistent with other studies. The number of false positive results increases relatively to the number of true positives, it leads to a number of more unnecessary caesarean sections performed on women at low risk [13].

There is plenty of papers which analyse the role of cardiotocography in pathological pregnancies. Wolf et al. [14], concludes that strict protocol composed of CCTG and fetal arterial Doppler is likely to be more effective to prevent fetal death than visual CTG alone in early preterm fetal growth restriction. Also, betamethasone, which is used to enhance fetal lung maturation in case of threatened preterm labour could change fetal heart variability [15]. Mullines et al. [13], present advantages and disadvantages of computer CTG. The authors state that continuous fetal monitoring is associated with lower early neonatal and overall infant mortality. On the other hand, as the decisions are made based on the CTG, it increases the rate of caesarean section and instrumental delivery.

The advantage of the study is clear methodology, using objective procedure for fetus monitoring and approachable presentation of results. The disadvantage is lack of other tools to monitor fetal state, e.g., ultrasonography [including Doppler and cerebroplacental ratio (CPR)]. What is more, the analysis of STV and APGAR score, in place of neonatal blood gas analysis might also be considered a drawback. In the hospital we work in, umbilical artery blood gas analysis [UBGA] is not performed routinely. These limitation leads to evaluation of neonatal state based on APGAR scale.

\section{CONCLUSIONS}

High specificity and negative predictive value of STV indicates a good Apgar score of newborns in term pregnancies. Good STV values indicate the high probability of bearing healthy child. Analysis of STV in preterm pregnancy is not clear. Examining fetal well-being in preterm pregnancy should include STV and other non-invasive and invasive procedures. Further research is needed.

\section{Conflict of interest}

The authors report no conflict of interest.

\section{Ethical approval}

All procedures performed in the studies involving human participants were in accordance with the ethical stan- dards of the institutional and/or national research committee and with the 1964 Declaration of Helsinki and its later amendments or comparable ethical standards. Informed consent was obtained from all individual participants included in the study.

\section{REFERENCES}

1. Wretler $\mathrm{S}$, Holzmann $\mathrm{M}$, Graner $\mathrm{S}$, et al. Fetal heart rate monitoring of short term variation (STV): a methodological observational study. BMC Pregnancy Childbirth. 2016; 16: 55, doi: 10.1186/s12884-016-0845-8, indexed in Pubmed: 26984160.

2. Galazios G, Tripsianis G, Tsikouras P, et al. Fetal distress evaluation using and analyzing the variables of antepartum computerized cardiotocography. Arch Gynecol Obstet. 2010; 281(2): 229-233, doi: 10.1007/s00404009-1119-8, indexed in Pubmed: 19455348.

3. WHO recommendations on intervention to improve preterm birth outcomes. https://apps.who.int/iris/bitstream/handle/10665/183037/ /? sequence $=1$

4. Leeflang MMG. Systematic reviews and meta-analyses of diagnostic test accuracy. Clin Microbiol Infect. 2014; 20(2): 105-113, doi: 10.1111/14690691.12474, indexed in Pubmed: 24274632.

5. Hoo ZH, Candlish J, Teare D. What is an ROC curve? Emerg Med J. 2017; 34(6): 357-359, doi: 10.1136/emermed-2017-206735, indexed in Pubmed: 28302644.

6. Cnattingius S, Norman M, Granath F, et al. Apgar Score Components at 5 Minutes: Risks and Prediction of Neonatal Mortality. Paediatr Perinat Epidemiol. 2017; 31(4): 328-337, doi: 10.1111/ppe.12360, indexed in Pubmed: 28493508.

7. Simon R. Sensitivity, Specificity, PPV, and NPV for Predictive Biomarkers. J Natl Cancer Inst. 2015; 107(8), doi: 10.1093/jnci/djv153, indexed in Pubmed: 26109105.

8. Bandos Al, Guo B, Gur D. Estimating the Area Under ROC Curve When the Fitted Binormal Curves Demonstrate Improper Shape. Acad Radiol. 2017; 24(2): 209-219, doi: 10.1016/j.acra.2016.09.020, indexed in Pubmed: 27884464.

9. Pinas A, Chandraharan E. Continuous cardiotocography during labour: Analysis, classification and management. Best Pract Res Clin Obstet Gynaecol. 2016; 30:33-47, doi: 10.1016/j.bpobgyn.2015.03.022, indexed in Pubmed: 26165747.

10. Leszczynska-Gorzelak B, Poniedzialek-Czajkowska E, Oleszczuk J. Intrapartum cardiotocography and fetal pulse oximetry in assessing fetal hypoxia. Int J Gynaecol Obstet. 2002; 76(1): 9-14, doi: 10.1016/s00207292(01)00545-8.

11. Gyllencreutz E, Lu Ke, Lindecrantz K, et al. Validation of a computerized algorithm to quantify fetal heart rate deceleration area. Acta Obstet Gynecol Scand. 2018; 97(9): 1137-1147, doi: 10.1111/aogs.13370, indexed in Pubmed: 29768660.

12. Giuliano N, Annunziata ML, Esposito FG, et al. Computerised analysis of antepartum foetal heart parameters: New reference ranges. J Obstet Gynaecol. 2017; 37(3): 296-304, doi: 10.1080/01443615.2016.1239069, indexed in Pubmed: 27923290.

13. Mullins $E$, Lees $C$, Brocklehurst $P$. Is continuous electronic fetal monitoring useful for all women in labour? BMJ. 2017; 359: j5423, doi: 10.1136/bmj. j5423, indexed in Pubmed: 29208652.

14. Wolf $\mathrm{H}$, Gordijn $\mathrm{SJ}$, Onland W, et al. Computerized fetal heart rate analysis in early preterm fetal growth restriction. Ultrasound in Obstetrics \& Gynecology. 2020; 56(1): 51-60, doi: 10.1002/uog.21887.

15. Verdurmen KMJ, Warmerdam GJJ, Lempersz C, et al. The influence of betamethasone on fetal heart rate variability, obtained by non-invasive fetal electrocardiogram recordings. Early Hum Dev. 2018; 119: 8-14, doi: 10.1016/j.earlhumdev.2018.02.011, indexed in Pubmed: 29505915. 